\title{
The prevalence of anxiety symptoms and associated factors among Nigerians newly posted for National Youth Service Corps programme in North-Western Nigeria.
}

\author{
*Amoko A. ${ }^{1}$, Ayodapo A.O. ${ }^{2}$, Dele T.O. ${ }^{3}$, Abitare H. ${ }^{3}$
}

\begin{abstract}
Objectives: This study was done to determine the prevalence of anxiety symptoms and assess the associated factors among new members of national youth service corps (NYSC) programme in NorthWestern Nigeria.

Method: A clinic-based descriptive cross-sectional study with convenient sampling method using selfadministered questionnaires was done among 157,2018 Batch-C, corps members at Dakingari orientation camp in Kebbi State, over a period of three weeks. The prevalence of anxiety symptoms was determined using anxiety subset of Hospital Anxiety and Depression scale. Data were analyzed with SPSS-16 and Chi-square was used to assess the degree of association between anxiety symptoms and certain factors. Pvalue of less than 0.05 was considered statistically significant.
\end{abstract}

Results: The prevalence of anxiety symptoms was $50.0 \%$ among the respondents. There was a significant association between the presence of anxiety symptoms and age of the respondents $(\mathrm{P}$-value $=0.006)$.

Conclusion: The high prevalence of anxiety symptoms among the new NYSC members suggests the need to take preventive measures such as incorporation of subjects on what should be expected during service year into the undergraduate learning curriculum. Doctors attending to youth corps members, especially when on camp, should routinely screen them for anxiety symptoms.

Key words: Prevalence, anxiety symptoms, youth, Nigeria.

*Corresponding Author

Amoko A.

ORCID-NO: http://orcid.org/0000-0002-5565-4314

E-Mail:amokojt@yahoo.com

\footnotetext{
${ }^{1}$ Department of Family Medicine, University of Ilorin Teaching Hospital, Ilorin, Nigeria.

${ }^{2}$ Department of Family Medicine, University College Hospital, Ibadan, Nigeria.

${ }^{3}$ Department of Family Medicine, Federal Medical Centre, Birnin-Kebbi, Nigeria
} 


\title{
La prévalence des symptômes d'anxiété et des facteurs associés chez les Nigérians nouvellement affectés au programme National Youth Service Corps dans le nord-ouest du Nigeria
}

\author{
*Amoko A. ${ }^{1}$, Ayodapo A.O. ${ }^{2}$, Dele T.O. ${ }^{3}$, Abitare H. ${ }^{3}$
}

\section{Resume}

Objectifs: Cette étude a été réalisée pour déterminer la prévalence des symptômes d'anxiété et évaluer les facteurs associés chez les nouveaux membres du programme national Youth Service Corps (NYSC) dans le nord-ouest du Nigeria.

Méthode: Une étude transversale descriptive en clinique avec une méthode d'échantillonnage pratique utilisant des questionnaires auto-administrés a été réalisée auprès de 157 membres du groupe C 2018 au camp d'orientation de Dakingari dans l'État de Kebbi, sur une période de trois semaines. La prévalence des symptômes d'anxiété a été déterminée à l'aide du sous-ensemble d'anxiété de l'échelle Hospital Anxiety and Depression. Les données ont été analysées avec SPSS-16 et le chi carré a été utilisé pour évaluer le degré d'association entre les symptômes d'anxiété et certains facteurs. Une valeur $\mathrm{p}$ inférieure à 0,05 a été considérée comme statistiquement significative.

Résultats: La prévalence des symptômes d'anxiété était de 50,0\% parmi les répondants. Il y avait une association significative entre la présence de symptômes d'anxiété et l'âge des répondants (valeur $\mathrm{p}=$ $0,006)$.

Conclusion: La forte prévalence des symptômes d'anxiété parmi les nouveaux membres du NYSC suggère la nécessité de prendre des mesures préventives telles que l'incorporation de sujets sur ce qui devrait être attendu pendant l'année de service dans le programme d'apprentissage de premier cycle. Les médecins qui s'occupent des membres du corps des jeunes, en particulier lorsqu'ils sont au camp, devraient systématiquement les dépister pour les symptômes d'anxiété.

Mots clés: Prévalence, symptômes d'anxiété, jeunes, Nigéria.

*Corresponding Author Amoko A.

ORCID-NO: http://orcid.org/0000-0002-5565-4314

Email:amokojt@yahoo.com

${ }^{1}$ Department of Family Medicine, University of Ilorin Teaching Hospital, Ilorin, Nigeria.

${ }^{2}$ Department of Family Medicine, University College Hospital, Ibadan, Nigeria.

${ }^{3}$ Department of Family Medicine, Federal Medical Centre, Birnin-Kebbi, Nigeria 


\section{INTRODUCTION:}

Anxiety symptoms are among the most common mental symptoms encountered in general medical practice and are capable of causing suffering with huge negative impact on life (1). Anxiety can be described as a negative emotion that occurs in response to perceived threats that come from internal or external source and can be real or imagined (2). Anxiety, on one hand, can be adaptive and protective when it triggers coping responses that protects an individual from a threat; on the other hand, it can be a disorder when it increases or persists to a degree that the affected individual can no longer function effectively in everyday living (2). According to the findings from the global burden of disease, injury and risk factors study in 2015 (3), anxiety disorders were the ninth leading contributors to the years lived with disability (YLDs) (3).

National Youth Service Corps (NYSC) is a year mandatory programme that tertiary institution graduates of ages 30 years and below undergo before being absorbed into labour market in Nigeria; psychosocial problems developed during this year can extend into the subsequent years of life, impairing the quality of life lived by the affected youths and rendering them less productive.

The NYSC programme consists of an initial three weeks of orientation which involves military drills with some social and academic training to prepare the corps members for their service year and the labour market. Corps members are then subsequently posted to various local government areas of the state where they complete the programme.

Service year is usually shortly after graduation, and corps members do not have absolute control on where to be posted. The anticipation of where to be posted and the need to adjust to new environment when posted, particularly when on orientation camp, is capable of precipitating psychological disturbances such as anxiety in the youth corps members.

Anxiety disorders have been shown to be common among young people especially during the school years. Ibrahim et al. (4) in 2013 found a prevalence of $34.9 \%$ for morbid anxiety among female medical students at King Abdulaziz University, Jeddah, Saudi-Arabia. The predictors of morbid anxiety according to the study were presence of depression, and academic and emotional failures (4).

A study conducted by Frank-Briggs et al. (5) in 2010 among secondary school student in
Nigeria showed that $91(10.28 \%)$ of 885 students interviewed met criteria for diagnosis of either anxiety or depression. Another study conducted by Bella-Awusah et al. (6) among University of Ibadan students, South-West, Nigeria, showed life-time and 12 -month prevalence of $9.4 \%$ and $8.5 \%$ respectively for social phobia, a type of anxiety disorder, among the undergraduates.

A previous study done among corps members in different local government areas of Kebbi state by Balami (7) in 2015 showed a prevalence of $54.5 \%$ for anxiety among the respondents. The identified risk factors for anxiety in this study were male gender and being from north-central part of the country.

The objective of our study was to determine the prevalence of anxiety symptoms and the associated factors among new NYSC members at Dakingari orientation camp, Kebbi State, North-West Nigeria.

\section{MATERIALS AND METHODS Study location}

This study was conducted at Dakingari NYSC orientation camp in Kebbi State, NorthWest Nigeria. Dakingari orientation camp, like every other NYSC orientation camp in the country, receives tertiary institution graduates from different parts of the country. However, majority of the graduates posted to the orientation camp are from the southern parts of the country where the culture is quite different from the northern parts, since one of the aims of NYSC is to foster unity which in a way can be enhanced through understanding of one another's cultures.

\section{Study design}

The study was conducted as a clinic based descriptive cross-sectional study using self-administered questionnaires. It was meant to include as many respondents as possible among new corps members that attended the camp clinic during the 3 weeks of orientation programme using convenient sampling method. About 350 out of a total of 1050 newly posted 2018 Batch C NYSC members attended the clinic during the orientation programme. Each new corps member that accepted to participate in the study after the clinic consultation, was educated on what the study entailed and encouraged to complete all the sections of the questionnaire and ask for clarification where needed, before leaving the clinic. A total of 250 new corps members accepted to partake in the study but just 157 of them returned the questionnaires.

The inclusion criteria were being a newly 
posted NYSC member that attended the clinic within the three weeks of orientation, and granting consent to participate in the study. Individuals that were not newly posted NYSC members and the newly posted members that required emergency services were excluded from the study. A written consent was obtained from the participants by the consent form attached to the questionnaire. The study was conducted between the $15^{\text {th }}$ November, 2018 and the $5^{\text {th }}$ December, 2018.

\section{Instrument}

The presence and level of anxiety were determined using the anxiety subset of the Hospital Anxiety and Depression scale (8), a tool that has been shown to have good case-finding properties for both anxiety and depression in the general population and primary care clinics (9). There are 7-items for anxiety subset and each item has a score of 0-3 with lowest total score of zero and highest total score of 21 . Scores of $0-7$ is regarded as negative (no anxiety) and 8-21 as positive (presence of anxiety). In terms of severity, scores of 8-10 is mildly positive (mild anxiety), 11-14 is moderately positive (moderate anxiety) and $15-21$ is severely positive (severe anxiety) (9).

Each questionnaire was labeled with a number, the equivalent of which was written on the participant's hospital folder in order to be able to trace the participant should the participant tested positive to the screening tool. Respondents that tested positive to the screening tool were further subjected to specific diagnostic tools, and those that have anxiety disorders were counseled and treated with anxiolytics in the cases of mild forms while the moderate to severe cases were referred to the behavioral scientists at Federal Medical Centre, Birnin Kebbi.

\section{Data analysis}

All data collected were analyzed with statistical package for social sciences (SPSS)-16. Chi-square test was used to determine the level of significance of association between the presence of anxiety and the basic characteristics (sociodemographic characteristics, presenting symptoms and presence of chronic medical illness) of the respondents. P-value of less than 0.05 was considered as statistically significant and the confidence interval was set at $95 \%$. Clearance to conduct the study was obtained from the ethical review committee of Federal Medical Centre, Birnin Kebbi, Kebbi State.

\section{RESULTS}

A total of 250 copies of the questionnaires were given out during the study but only 157 copies were returned, giving a return rate of $62.8 \%$. 103 respondents fully completed the questionnaires, and 122 respondents completed questions in HAD scale anxiety subset section.

\section{Basic characteristics of the respondents}

Table I shows the basic characteristics of the respondents. The ages of the respondents range from 20 to 31 years with mean age of $26.42 \pm 2.55$ years. More than half of the respondents (63.8\%) were in the age group 26-30 years. Majority of the participants were male $(73.9 \%)$ and the male to female ratio was 2.8:1. The Igbo ethnic group had the highest representation (38.5\%) while the Hausa had the least representation (5.8\%).

More than $80 \%$ of the respondents were Christians, and only $12.2 \%$ of the respondents were married. More respondents graduated from University (67.7\%) and more spent 4 years and below in the tertiary institution before graduation $(66.7 \%)$. In respect to duration between the year of graduation and call-up for the NYSC programme, $47.4 \%$ spent less than 1 year before call-up while $46.7 \%$ spent between 1 and 2 years before call-up, and only $5.9 \%$ spent more than 2 years before call-up. About $30 \%$ of the respondents had chronic medical illness and close to half $(48.1 \%)$ of the respondents presented to the clinic with vague (non-specific) symptoms.

\section{Prevalence and severity of anxiety symptoms}

Table II shows the prevalence of anxiety symptoms among the respondents while table III shows the severity of the anxiety. Half of the respondents $(50.0 \%)$ that completed questions on anxiety symptoms had anxiety symptoms; more than $90 \%$ of the respondents with anxiety symptoms had mild to moderate forms (mild$42.6 \%$ and moderate- $49.2 \%$ ) while only $8.2 \%$ had the severe form.

\section{Association between the presence of anxiety symptoms and the basic characteristics of the respondents}

Table IV shows the association between the presence of anxiety symptoms and basic characteristics of the respondents. Respondents in the age group of 20 years and below had the highest prevalence $(100 \%)$, followed by those in the age group 26-30 years (59.4\%) and then those 
in the age group 21-25 years (35.6\%). None of the respondents in age group of above 30 years had anxiety symptoms $(0.0 \%)$. This relationship was statistically significant $(\mathrm{p}=0.006)$. There was, however, no significant association between the presence of anxiety symptoms and other sociodemographic characteristics of the respondents.

The prevalence of anxiety symptoms was much higher among respondents who had chronic medical illness (61.5\%) than those who had no chronic medical illness $(45.1 \%)$, this relationship was however not statistically significant $(p=0.091)$. Respondents who presented to the clinic at the time of administering the questionnaires with vague (non-specific) symptoms had higher prevalence of anxiety symptoms $(50.0 \%)$ than those who presented with specific symptoms $(47.2 \%)$ this relationship was also not statistically significant $(\mathrm{p}=0.774)$.

\section{DISCUSSION}

This study assessed the prevalence of anxiety symptoms and the associated factors among new NYSC members at the Dakingari orientation camp in Kebbi State, North-West Nigeria. Like in many previous studies on anxiety disorders among young people, the prevalence of anxiety symptoms in this study was high (50.0\%). This finding is similar to the finding in a study earlier conducted among NYSC members at their various places of primary assignments in Kebbi State by Balami (7). Balami's study found a prevalence of $54.5 \%$ for anxiety among the corps members (7). A study conducted by Lamidi et al. (10) on depression, anxiety and stress among young people attending a private university in South-West Nigeria, revealed a prevalence of as high as $67.8 \%$ for anxiety (10). Another study, a multicentre study, done among university pharmacy students in different parts of Nigeria by Aluh et al. (11) also revealed a high prevalence of anxiety $(63.5 \%)$.

Though not as high as in our study in most cases, high prevalence rates of anxiety symptoms and disorders have been recorded among young people in the other parts of the world. A study conducted by Ibrahim et al. (4) in 2013 among female medical students in King Abdulaziz university, Jeddah, Saudi-Arabia, found prevalence of $34.9 \%$ for morbid anxiety. Findings from New Zealand Mental Health Survey (NZMHS), the Dutch Tracking Adolescents Individual Lives Survey (TRAILS), the US National Co-morbidity Survey (NCS) and its replication (NCS-R), and the Children in the Community Study from US (CICS) also showed a fairly high prevalence of anxiety among young people. The findings showed that the 12 -month prevalence of anxiety disorders (including specific phobias) among young adults was between $19.4 \%$ and $22.3 \%$ (5). A population based study done in Brazil on anxiety disorders among young people by Mondi et al. (12) revealed a moderately high prevalence $(20.9 \%)$ of anxiety disorders among the participants.

Prevalence of anxiety symptoms and disorders among young adults has been shown to be higher than the general population. According to the information obtained from our world in data, the global prevalence of anxiety disorders in general population ranges between $2.5 \%$ and $7 \%$ (13). A Lagos State Mental Health Survey done by Adewuya et al. (14) in 2017 in South-West Nigeria showed a low weighted current prevalence $(3.5 \%)$ for symptoms of generalized anxiety in the general population. A systematic review and meta-regression on global prevalence of anxiety disorders among the general population by Baxter et al. (15) estimated current prevalence of anxiety disorders to range between $0.9 \%$ and $28.3 \%$ in the general population.

Certain factors have been implicated to be possibly responsible for higher prevalence of anxiety symptoms among young adults. Some of these factors are linked to challenges that come with the emerging adulthood stage of life (ages 18 years to 29 years) (16). These challenges include the tasks of completing education and building a stable life structure (16). This stage of life is also characterized by changes in love and work life (16). Some of the people at this stage of life also have to combine responsibilities such as schooling and working together (16).

In addition to the general factors stated above as causes of higher prevalence of anxiety symptoms among young adults, we believe that separation from loved ones and familiar environment as well as need to adjust to new environment and activities may be a major factor responsible for the high prevalence of anxiety symptoms among the respondents in our study. From our one on one interaction with some corps members during clinic consultations, we discovered that some corps members had never traveled out of their states of origins and were afraid of coming to the northern part of the country because of the security situation there.

The other possible reason for high prevalence of anxiety symptoms among the new NYSC members in this study is the fear of where they will be posted for the primary assignment after completion of the orientation programme as 
there were many NYSC officials that attested to the fact that they had been approached by some NYSC members to help them influence their postings into urban areas and places of primary assignment where a reasonable stipends will be paid in addition to their regular allowances. The uncertainty of the financial states during the NYSC programme, is also a possible factor that could be responsible for high prevalence of anxiety symptoms among the respondents. This is because some parents and guardians tend to withdraw their financial supports for their children and wards in line of their beliefs that the children or wards have started earning salaries and should be able to take care of themselves. Another possible factor for high prevalence of anxiety in this study is the fear of getting a good job after completion of the NYSC programme considering the high unemployment rate in the country.

In this study, looking at the factors that could possibly be associated with the presence of anxiety symptoms among the respondents, we considered some basic characteristics which include socio-demographic characteristics, symptoms at presentation, presence of chronic medical illness, and factors that are related to the type of institution graduated from, time of graduation and time of call-up for NYSC. The study showed higher prevalence of anxiety symptoms among female gender, Igbo tribe, Muslims, graduates of university, graduates that spent more than 4 years at the tertiary institution, those that received call-up for service in less than 1 year after graduation, those with chronic medical illness and those that presented with nonspecific symptoms; these relationships were however not statistically significant. There is however a significant association between the respondent age groups and the presence of anxiety symptoms $(p=0.006)$. The association was such that the youngest respondents had the highest prevalence of anxiety symptoms while the oldest ones had no case. This finding may be due to the differences in the ability to cope with separation from loved ones and familiar environment, and adjust to new environment and activities by the different age groups. Older youths are more likely to have traveled away from home and be separated from their loved ones and familiar environment than the younger youths. Older youths are also likely to have confronted more life challenges, the experience of which may have helped them adjusted faster to the new environment and activities. Some studies have also shown age-related decline in prevalence of anxiety disorders among adults such that younger adults have higher frequency of anxiety disorders than the older ones $(17,18)$.

The findings from this study shows the need for doctors attending to new corps members to often consider the possibility of anxiety disorders during consultation and possibly routinely screen the corps members for anxiety symptoms.

Limitations of the study: This study was conducted as a clinic-based cross-sectional study through self-administered questionnaires with the use of convenient sampling technique. Out of the 250 questionnaires given out, just 157 questionnaires were returned (response rate of $62.8 \%$ ). The study was also done in only one out of the several orientation camps in North-West Nigeria and during a single orientation period. All these should be put into consideration in generalizing the information provided by the study.

Recommendation: we want to recommend that this kind of study will get better if conducted as community-based multi-centre studies in which there will be chance of involving many new NYSC members in different orientation camps across the country. This may help increase the significance of the study, and find significant association between some of the factors that were found to be associated with higher prevalence of anxiety disorders but not statistically significant in our study.

\section{CONCLUSION}

This study shows a high prevalence of anxiety symptoms among new NYSC members particularly the younger ones; it is therefore important for healthcare providers attending to this group of patients to bear this in mind and possibly routinely screened them for anxiety symptoms. Efforts should also be made to reduce this high prevalence by possibly incorporating teaching on what NYSC entails and what is expected of the members into the curriculum of undergraduate students. NYSC management should also try and include discussion on anxiety and some other common health problems among young people as part of the lectures during the orientation programme.

Conflicts of interest: All financial obligations as regard this study were borne by the researchers, and there was no involvement of any party that could result to conflict of interest. 
Acknowledgements: We want to acknowledge the entire 2018 Batch-C Dakingari orientation camp health team, particularly the corps doctors, for their immense supports during this study.

\section{REFERENCES}

1. Sareen J, Jacobi F, Cox BJ, Belik S-LL, Clara I, Stein MB. Disability and poor quality of life associated with comorbid anxiety disorders and physical conditions. Arch Intern Med. 2006;166:2109-16.

2. Moser DK. "The rust of life": Impact of anxiety on cardiac patients. Am J Crit Care. 2007;16:361-9

3. Global Burden of Disease 2015 Diseases and Injury Incidence and Prevalence Collaborators. Global, regional, and national incidence, prevalence, and years lived with disabilities for 210 diseases and injuries, 1990-2015: a systematic analysis for Global Burden of Disease study. Lancet 2016; 388 (10053):1546-1602.

4. Ibrahim I, Al-Kharboush D, El-Khatib L, ALHabib A, Asali D. Prevelance and predictors of anxiety and depression among female medical students in King Abdulaziz University, Jeddah, Saudi-Arabia. Iran J Public Health 2013;42(7):726-36

5. Frank-Briggs AI, Alikor E.A. Anxiety disorder amongst secondary school children in an urban city in Nigeria. Int J Biomed Sci 2010; 6(3):24641
6. Bella TT, Omigbodun OO. Social phobia in Nigerian university students: prevalence, correlates and co-morbidity. Soc Psychiatry Psychiatric Epidemiol. 2009;44(6)458-63

7. Balami AD. Depression, anxiety, stress and their associated factors among corps members serving in Kebbi state. Niger J Med 2015:24(3):223-32.

8. Zigmond AS, Snaith RP. The hospital anxiety and depression scale (HADS). Acta Psychiatr Scand. 1983;67(361-370):361-70.

9. Snaith RP. The Hospital Anxiety And Depression Scale. Health Qual Life Outcomes. 2003;1:29.

10. Lamidi RE. Prevalence and correlates of depression, anxiety and academic stress among science students in Oduduwa University, Ile-Ife, Nigeria. Texila International Journal 2013;4(3). DOI: $10.21522 /$ TIJPH2013.04.03Art001 A v a i 1 a b l e a t https://www.texilajournal.com/publichealth/article/512-prevalence-and-correlates Accessed on 10/10/2020

11. Aluh DO, Abba A, Afosi AB. Prevalence and correlates of depression, anxiety disorders and stress among undergraduates pharmacy students in Nigeria. Pharmacy Education 2020;25(1):236248.

12. Mondi TS, Konradt CE, Cardoso TA, Quevedo LA, Jasen K, Mattos LD et al. Anxiety disoders in young people: a population based study. Rev. Bras. Psiquiatr. [Internet]; 2013 Dec. Available at

How to cite this article:

Amoko A., Ayodapo A.O., Dele T.O., Abitare H. The prevalence of anxiety symptoms and associated factors among Nigerians newly posted for National Youth Service Corps programme in North-Western Nigeria. Research Journal of Health Sciences, 2021, 9(3): 236-244 
Table 1: Basic characteristics of the respondents

\begin{tabular}{|c|c|c|}
\hline Variable & Frequency & Percentage \\
\hline \multicolumn{3}{|l|}{ Age groups(Years) $\mathrm{N}=152$} \\
\hline$=20$ & 1 & $0.7 \%$ \\
\hline $21-25$ & 50 & $32.9 \%$ \\
\hline $26-30$ & 97 & $63.8 \%$ \\
\hline$>30$ & 4 & $2.6 \%$ \\
\hline \multicolumn{3}{|l|}{ Gender. $N=157$} \\
\hline Male & 116 & $73.9 \%$ \\
\hline Female & 41 & $26.1 \%$ \\
\hline \multicolumn{3}{|l|}{ Tribe. $\mathrm{N}=156$} \\
\hline Hausa & 9 & $5.8 \%$ \\
\hline Yoruba & 38 & $24.3 \%$ \\
\hline Igbo & 60 & $38.5 \%$ \\
\hline Other tribes & 49 & $31.4 \%$ \\
\hline \multicolumn{3}{|l|}{ Religion. $\mathrm{N}=157$} \\
\hline Christianity & 130 & $82.8 \%$ \\
\hline Islam & 26 & $16.6 \%$ \\
\hline Traditional & 1 & $0.6 \%$ \\
\hline \multicolumn{3}{|l|}{ Marital Status. $\mathrm{N}=156$} \\
\hline Married & 19 & $12.2 \%$ \\
\hline Single & 137 & $87.8 \%$ \\
\hline \multicolumn{3}{|l|}{ Tertiary Institution Attended } \\
\hline \multicolumn{3}{|l|}{$\mathrm{N}=155$} \\
\hline Polytechnics & 50 & $32.3 \%$ \\
\hline University & 105 & $67.7 \%$ \\
\hline \multicolumn{3}{|l|}{$\begin{array}{l}\text { Year spent in tertiary institution. } \mathrm{N}=153 \\
=4 \mathrm{yrs}\end{array}$} \\
\hline \multirow[t]{2}{*}{$>4 \mathrm{yrs}$} & 102 & $66.7 \%$ \\
\hline & 51 & $33.3 \%$ \\
\hline \multicolumn{3}{|l|}{$\begin{array}{l}\text { Duration between graduation and call-up } \\
\mathrm{N}=135\end{array}$} \\
\hline$<1 \mathrm{yr}$ & 64 & $47.4 \%$ \\
\hline $1-2 y r s$ & 63 & $46.7 \%$ \\
\hline$>2 \mathrm{yrs}$ & 8 & $5.9 \%$ \\
\hline \multicolumn{3}{|l|}{ Past Medical History. $\mathrm{N}=156$} \\
\hline Presence of chronic medical illness & 48 & $30.8 \%$ \\
\hline Absence of chronic medical illness & 108 & $69.2 \%$ \\
\hline \multicolumn{3}{|l|}{ Presenting symptoms. $\mathrm{N}=133$} \\
\hline Specific symptoms & 69 & $51.9 \%$ \\
\hline Non-specific (vague) symptoms & 64 & $48.1 \%$ \\
\hline
\end{tabular}

$\mathrm{N}=$ total number of respondents.

Table 2: Prevalence of anxiety symptoms using the HAD scale anxiety subset score. $\mathrm{N}=122$

\begin{tabular}{ll}
\hline Anxiety status & Frequency (\%) \\
\hline No Anxiety Disorder & $61(50.0)$ \\
Presence of Anxiety Disorder & $61(50.0)$ \\
Total & $122(100.0)$ \\
\hline$\%=$ percent &
\end{tabular}


Table 3: Level (severity) of anxiety disorder using the HAD scale, anxiety subset score. $\mathrm{N}=61$

\begin{tabular}{ll}
\hline $\begin{array}{l}\text { Level of severity of the } \\
\text { anxiety symptoms }\end{array}$ & Frequency (\%) \\
\hline Mild & $26(42.6)$ \\
Moderate & $30(49.2)$ \\
Severe & $5(8.2)$ \\
Total & $61(100)$ \\
\hline$\%=$ percent &
\end{tabular}

Table 4: Association between presence of anxiety symptoms and basic characteristics of the respondents

\begin{tabular}{|c|c|c|c|c|c|}
\hline Variable & $\begin{array}{l}\text { No Anxiety. } \\
\text { Frequency } \\
(\%)\end{array}$ & $\begin{array}{l}\text { Presence of } \\
\text { Anxiety. } \\
\text { Frequency } \\
\text { (\%) }\end{array}$ & $\begin{array}{l}\text { Total } \\
(\%)\end{array}$ & $\mathbf{X}^{2}$ & $\begin{array}{l}\text { P- } \\
\text { value }\end{array}$ \\
\hline \multicolumn{6}{|l|}{ Age groups(yrs) $\mathrm{N}=118$} \\
\hline$=20$ & $0(0.0)$ & $1(100)$ & 1(100) & & \\
\hline $21-25$ & $29(64.4)$ & $16(35.6)$ & $45(100)$ & & \\
\hline $26-30$ & $28(40.6)$ & $41(59.4)$ & $69(100)$ & & \\
\hline$>30$ & $3(100)$ & $0(0.0)$ & $3(100)$ & & $* 0.006$ \\
\hline \multicolumn{6}{|l|}{ Gender. $N=122$} \\
\hline Male & $49(52.7)$ & $44(47.3)$ & $93(100)$ & & \\
\hline Female & $12(41.4)$ & $17(58.6)$ & $29(100)$ & 1.131 & 0.288 \\
\hline \multicolumn{6}{|l|}{ Tribe $N=122$} \\
\hline Hausa & $4(66.7)$ & $2(33.3)$ & $6(100)$ & & \\
\hline Yoruba & $18(58.1)$ & $13(41.9)$ & $31(100)$ & & \\
\hline Igbo & $21(44.7)$ & $26(55.3)$ & $47(100)$ & & \\
\hline Other tribes & $18(47.4)$ & $20(52.6)$ & $38(100)$ & & ${ }^{*} 0.565$ \\
\hline \multicolumn{6}{|l|}{ Religion. $\mathrm{N}=122$} \\
\hline Christianity & $51(50.0)$ & $51(50.0)$ & $102(100)$ & & \\
\hline Islam & $9(47.4)$ & $10(52.6)$ & $19(100)$ & & \\
\hline Traditional & $1(100)$ & $0(0.0)$ & $1(100)$ & & ${ }^{*} 1.000$ \\
\hline \multicolumn{6}{|l|}{ Marital Status. $\mathrm{N}=122$} \\
\hline Married & $6(50.0)$ & $6(50.0)$ & $12(100)$ & & \\
\hline Single & $55(50.0)$ & $55(50.0)$ & $110(100)$ & 0.000 & 1.000 \\
\hline \multicolumn{6}{|l|}{ Tertiary Institution Attended. $\mathrm{N}=121$} \\
\hline Polytechnics & $19(52.8)$ & $17(47.2)$ & $36(100)$ & & \\
\hline University & $41(48.2)$ & $44(51.8)$ & $85(100)$ & 0.209 & 0.649 \\
\hline \multicolumn{6}{|l|}{ Year spent in tertiary institution. $\mathrm{N}=119$} \\
\hline$=4 \mathrm{yrs}$ & $39(51.3)$ & $37(48.7)$ & $76(100)$ & & \\
\hline$>4 y r s$ & $19(44.2)$ & $24(55.8)$ & $43(100)$ & 0.559 & 0.451 \\
\hline \multicolumn{6}{|l|}{$\begin{array}{l}\text { Duration between graduation and call-up } \\
\mathrm{N}=109\end{array}$} \\
\hline$<1 \mathrm{yr}$ & $24(48.0)$ & $26(52.0)$ & $50(100)$ & & \\
\hline $1-2 y r s$ & $26(50.0)$ & $26(50.0)$ & $52(100)$ & & \\
\hline$>2 \mathrm{yrs}$ & $4(57.1)$ & $3(42.9)$ & $7(100)$ & & ${ }^{*} 0.913$ \\
\hline \multicolumn{6}{|l|}{ Past Medical History. $\mathrm{N}=121$} \\
\hline Presence of chronic medical illness & $15(38.5)$ & $24(61.5)$ & $39(100)$ & & \\
\hline Absence of chronic medical illness & $45(54.9)$ & $37(45.1)$ & $82(100)$ & 2.849 & 0.091 \\
\hline \multicolumn{6}{|l|}{ Presenting symptoms. $\mathrm{N}=103$} \\
\hline Specific symptoms & $28(52.8)$ & $25(47.2)$ & $53(100)$ & & \\
\hline Non-specific (vague) symptoms & $25(50.0)$ & $25(50.0)$ & $50(100)$ & 0.083 & 0.774 \\
\hline
\end{tabular}

*Fishers Exact Test, $\mathrm{X}^{2}$-Chi-square value, N-Total number of respondents, Yrs-Years, $\%=$ percent 